\title{
Process of removing the bitter taste of pomelo peel
}

\author{
Son H.N ${ }^{1}$, Thi V.L ${ }^{1}$, Hau Q.B ${ }^{1}$, Khang C.V ${ }^{2,3 *}$, and Cang H.M ${ }^{1 * *}$ \\ ${ }^{1}$ Faculty of Chemical Engineering and Food Technology, Nong Lam University, Thu Duc District, Ho \\ Chi Minh City, Vietnam \\ ${ }^{2}$ Institute of Environmental Sciences, Nguyen Tat Thanh University, Ho Chi Minh City, Vietnam \\ ${ }^{3}$ Faculty of Environmental and Food Engineering, Nguyen Tat Thanh University, Ho Chi Minh City, \\ Vietnam
}

\begin{abstract}
The de-bittering effects of immersion in ethanol on white pomelo peel was investigated. The suitable conditions for ethanol immersion were found as sample: ethanol ratio of $1 / 12(\mathrm{~g} / \mathrm{mL})$, immersion ethanol concentration $40^{\circ}$, immersion time 4 hours, immersion temperature $50^{\circ} \mathrm{C}$, discharge temperature $50^{\circ} \mathrm{C}$, and 3 rinsing times. Immersion with ethanol is highly effective as $82.5 \%$ naringin bitterness was removed and pesticide residue was reduced. However, the method also reduce content of vitamin C and sugar. Ethanol is one of the most used solvents for antioxidant extraction because it is inexpensive, reusable, non-toxic and used in the food industry. The de-bittering method by immersion with ethanol showed that large scale naringin was separated from the pomelo peel.
\end{abstract}

\section{Introdution}

Pomelo is a member of Rutaceae family that is originated from Southeast Asia, [1]. Pomelo is ranked as the fourth important citrus fruit for the global economic [2]. In Vietnam, a number of different varieties of pomelo is widely distributed accross the country, including Da Xanh (grown in Ben Tre province), Dien (grown in Hanoi city), Doan Hung (grown in Phu Tho province), Phuc Trach (grown in Ha Tinh province), and Nam Roi (grown in Vinh Long province). Pomelo is an abundant source of nutrients, phytochemicals, vitamin C, fiber and lycopene which is a well-recognized antioxidant [3]. Pomelo peel may promote wound healing in experimental animals. Pomelo peel has effect of reducing fat, anti-aging, treating skin inflammation, anti-acne.

The green and white peels of pomelo provide several health benefits such as preventing fatty liver diseases, reducing cholesterol, treating fiber deficiency and diabetes, as well as losing weight and aromatic therapy [4]. After processing, pomelo peel accounts for nearly $50 \%$ of the fruit weight [5]. However, a large amount of pomelo peel is considered a byproduct of pomelo consumption that is usually discarded to the environment as agricultural wastes. Recently, studies have been focused on utilizing agricultural wastes forconversion

\footnotetext{
${ }^{*}$ Corresponding author: vckhang@,ntt.edu.vn

** Corresponding author: maihuynhcang@hcmuaf.edu.vn
} 
and extraction of bioactive compounds and substances which can be used for fertilizer, soil modification, animal feed and health supplements [6]. However, pomelo peel contains flavonoids such as hesperidin, limonin, and naringin which interfere fruit juice processing and give rise to the bitter taste [7]. Specifically, naringin is a water-soluble glucoside that has about $20 \mathrm{mg} \mathrm{Kg}^{-1}$ in water and has detectable limit of less than $1.5 \mathrm{mg} \mathrm{Kg}^{-1}$ [8]. There are many different methods of isolating naringin, such as extraction with hot water under pressure [9], supercritical carbon dioxide [10], combined solvent, flash chromatography [11] and high-speed retrograde chromatography [12].

In which extraction of naringin by ethanol is a proven traditional method effectiveness [13]. Therefore, the de-bittering effects of immersion with ethanol was investigated. From there, the factors have been investigated and selected and the procedure of extracting naringine from pomelo ethanol solvent has been established with safety, low cost and high efficiency.

\section{Methodology}

\subsection{Material and chemicals}

Pomelo peel by-products were bought from small traders which sell pomelo juice at Thu Duc market, Kha Van Can street, Thu Duc district, HCMC. The chemicals used in this experiment include potassium permanganate, ethylene glycol, sodium hydroxide, lead acetate, sodium sulphuric, potassium sodium tartrate, starch paste (obtained from China).

\subsection{Naringin crystallization and contruction of the standard curve}

The procedure is as follows: weigh A total of $100 \mathrm{~g}$ of pomelopomelo peel was washed with water and dried at $75^{\circ} \mathrm{C}$ for $8 \mathrm{~h}$. The dried pomelo peel is placed intoa $1000 \mathrm{~mL}$ sonication bath, added with $1 \mathrm{~L}$ of absolute ethanol and ultrasonic extraction was performed twice, each time for $2 \mathrm{~h}$. Then, water was allowed to evaporate to about $170 \mathrm{~mL}$ at $\mathrm{pH} 6-7 . \mathrm{Ca}(\mathrm{OH})_{2}$ and $\mathrm{HCl}$ were used to adjust $\mathrm{Ph}$. ethanolNaringin crystallization was initiated by removing the solvent at $60-70{ }^{\circ} \mathrm{C}$ and allowed cooling down at room temperature for $24 \mathrm{~h}$. The naringin crystals obtained with large size and white color was washed with cold water for several times, then re-crystallized with water - EtOH (8:2) to obtain the purified naringin crystals with needle-shaped, ivory color and $90-95 \%$ of purity, which was used as the standard to establish the relationship between the content of naringin and the absorbance measurements (UV Vis-Itachi U5100). An amount of $0.1063 \mathrm{~g}$ of purified naringin crystals was diluted with methanol solvent to obtain a concentration of $1-5 \mathrm{mg} / \mathrm{mL}$ and establish the naringin standard curve.

\subsection{Experiment to reduce bitterness on pomelo peel}

Prior to the experiment, the obtained pomelo peels were washed thrice with water, allowed to dry for $30 \mathrm{~min}$ and removed the white shell. The peels were cut into cubes with $30 \times 10 \times 5$ $\mathrm{mm}$ in size.

A total of $5 \mathrm{~g}$ of samples were crushed and placed into a $250 \mathrm{~mL}$ flask containinga volume of $50 \mathrm{~mL}$ of absolute ethanol. The flask was placed the water bath at different temperatures for a period of 1-8 $\mathrm{h}$ to obtain the filtrate. Then the filtrate was washed with $50 \mathrm{~mL}$ of either absolute ethanol solution or salt water. Run the rinsing solution into the original flask in the water bath for $2 \mathrm{~h}$. Do the same three more times. After soaking in ethanol, rinse the pomelo peel with water several times with the rinse water temperature in the range $40-55^{\circ} \mathrm{C}$ to remove 
the ethanol smell and remove any remaining naringin. The experiment was carried out in 3 times.

\subsection{Analysis of the criteria}

Determination of moisture and ash in raw materials was in accordancewith the research by [14]. Determination of content of citric acid, $\mathrm{pH}$, vitamin $\mathrm{C}$ in pomelo peel followed the TCVN 4589: 1988, TCVN 7806: 2007, and TCVN 11168: 2015 standard. Quantification of glucose and sucrose in pomelo peel followed Bertrand and acid hydrolysis methods, respectively [15].

\subsubsection{Determination of naringin content}

A total of $5 \mathrm{~g}$ of white pomelo peel was accurately weighed and soaked in $50 \mathrm{ml}$ of ethanol. The filtrate was collected and 0.2 ML of which was mixed with $0.2 \mathrm{ml}$ of $4 \mathrm{~N} \mathrm{NaOH}$. Absorbance was measured at $420 \mathrm{~nm}$ of wavelength.The results of naringin content were obtained based on the standard curve and the following formula (1).

$$
\mathrm{C}_{2}=\frac{\mathrm{C}_{1} * \mathrm{~V}_{\mathrm{dm}}}{\mathrm{m}}
$$

Where:

$\mathrm{C} 1$ is the naringin content according to the standard curve $(\mathrm{mg} / \mathrm{ml})$.

$\mathrm{C} 2$ is the real naringin content $(\mathrm{mg} / \mathrm{g})$.

$\mathrm{Vdm}$ is the volume of solvent $(\mathrm{ml})$.

$\mathrm{m}$ is the original weight of pomelopomelo peel $(\mathrm{g})$

\subsubsection{Determination of the bitterness reduction efficiency}

Pomelo peel samples $(10 \mathrm{~g})$ pomelo was placed in a $250 \mathrm{ml}$ flask containing $200 \mathrm{ml}$ of ethanolethanol. A volume of $0.2 \mathrm{ml}$ of filtrate was mixed with $0.2 \mathrm{ml}$ of $4 \mathrm{~N} \mathrm{NaOH}$, and measured for absorbance at $420 \mathrm{~nm}$. The content of naringin in the original pomelo samples is calculated based on standard curve and regarded as $\mathrm{A}(\mathrm{mg} / \mathrm{g})$. The expeiment was continued by soaking $10 \mathrm{~g}$ of white peel in $50 \mathrm{ml}$ of ethanolethanol. The peel was ríned with $500 \mathrm{ml}$ of water. After 4 time of water-rinsing, $0.2 \mathrm{ml}$ of the solution was mixed with $0.2 \mathrm{ml}$ of $4 \mathrm{~N} \mathrm{NaOH}$ and absorbance measurement was performed at $420 \mathrm{~nm}$. The content of naringin in the pomelo samples after repetitive soaking with ethanol is calculated based on standard curve and regarded as B (mg/g). From the above results, the bitterness reduction efficiency was calculated by using equation (2).

$$
\mathbf{X}=\left(\frac{\mathbf{A}-\mathbf{B}}{\mathbf{A}}\right) * 100
$$

Where:

$\mathrm{X}$ is the bitterness reduction efficiency (\%).

A is the naringin content in the original pomelo sample $(\mathrm{mg} / \mathrm{g})$.

$\mathrm{B}$ is the naringin content in the pomelo sample after soaking with ethanol $(\mathrm{mg} / \mathrm{g})$. 


\section{Results and discussion}

\subsection{Identification of the main composition in the pomelo peel}

The peel of pomelo usually accounts for $46.58 \%$ of the total fruit weight. Specifically, the green-colored peel ( $48.574 \%$ of peel volume) is commonly used for essential oil extraction while the white peel (51.426\% of peel volume) has potential food applications. As pomelo peel material is environmental friendly and provides health benefits for human, it is necessary to take advantage of this source. The present study ultilizes the peel from a local variety of pomelo with an attempt to reduce its bitter taste by soaking with ethanol. The composition of the pomelo peel samples were analyzed and results were shown in Table 1.

Table 1. The composition of pomelo peel

\begin{tabular}{|c|c|}
\hline Composition & Ratio (\%) \\
\hline Whole peel / pomelo & $46.58 \pm 5.03$ \\
\hline Green peel / 1 kg of peel & $48.574 \pm 4.23$ \\
\hline White peel / 1 kg raw peel & $51.426 \pm 4.23$ \\
\hline
\end{tabular}

Table 2. Physical and chemical properties of raw materials

\begin{tabular}{|l|l|}
\hline Composition & \multicolumn{1}{|c|}{ Content } \\
\hline Humidity & $76.558 \pm 0.016 \%$ \\
\hline Ash (inorganic) & $0.677 \pm 0.003 \%$ \\
\hline $\mathrm{pH}$ & $5.153 \pm 0.03$ \\
\hline Acid citric & $2.219 \mathrm{mg} / \mathrm{g}$ \\
\hline Glucose & $0.2996 \%$ \\
\hline Sucrose & $0.5073 \%$ \\
\hline Vitamin C & $0.029 \pm 0.0018 \%$ \\
\hline
\end{tabular}

Table 2 shows the physical and chemical properties of pomelo samples. Pomelo. The samples has a high moisture of $76.558 \%$, which is suitable for microorganisms to grow and cause spoilage. To preserve the quality of the pomelo peel over an extended period of time, it is necessary to perform drying process. The low ash level $(0.667 \pm 0.003 \%)$ proved that the main composition of pomelo peel are organic substances that are easily decomposed, thus requiring storage at low temperature in order to avoid loss of nutrients and deterioration. pomelo peel samples have $\mathrm{pH}$ of 5.153 which can be an environment for fermentation and nutrient loss. The above results are different from the study of [16], where the moisture, ash, $\mathrm{pH}$ and vitamin $\mathrm{C}$ content of pomelo peels were reported as $84.128 \%, 0.617 \%, 5.267$ and $0.029 \%$ respectively. The content of citric, which is an environmental friendly cleaning agent and natural antioxidant in pomelo peel is $2.219 \mathrm{mg} / \mathrm{g}$. The total sugar content reached $0.8069 \%$ in the acidic environment. The results of total acid citric and total sugar contents obtained in the present study are higher than that obtained from National Institute Of Nutrition, where the $0.32 \mathrm{mg} / \mathrm{g}$ and $0.58 \%$, respectively. 


\subsection{Naringin crystallization and construction of the standard curve}

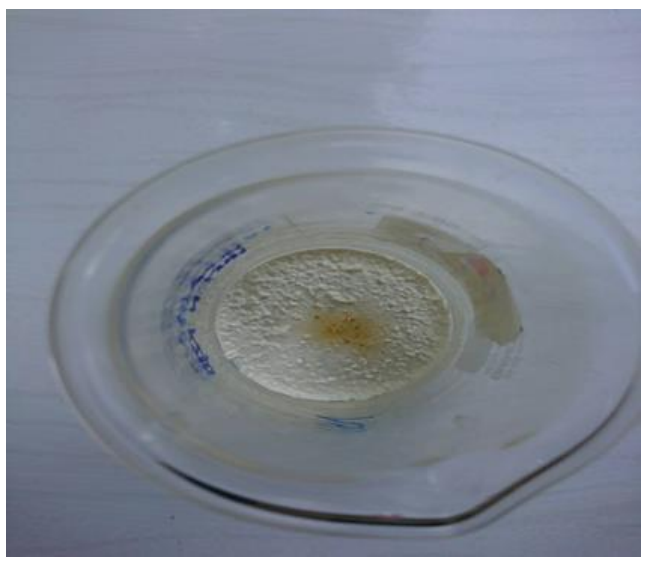

Fig. 1. Naringin image of naringin crystals

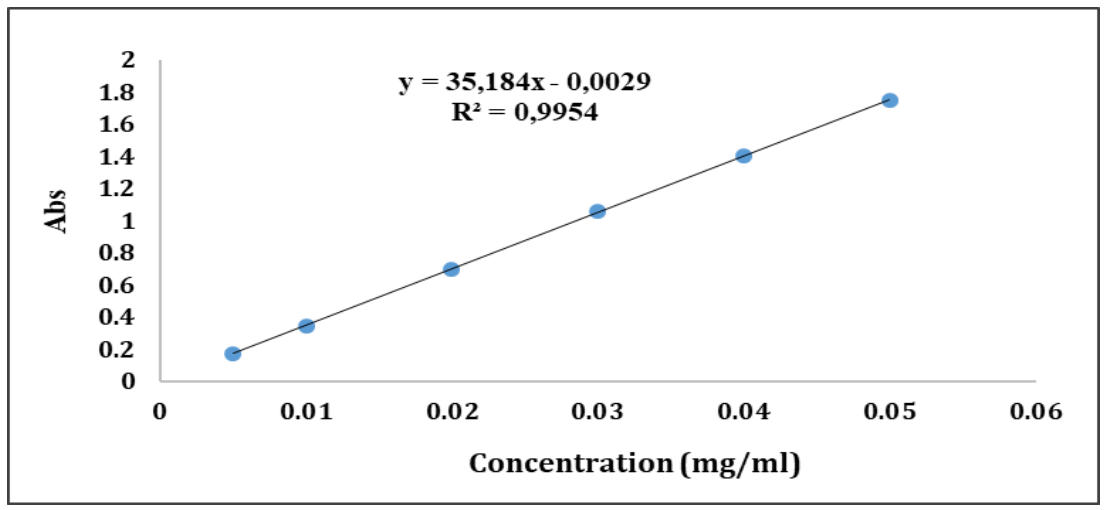

Fig. 2. Standard curve of naringin content

Figure 1 demonstrates the image of crystallized naringin. The obtained naringin crystal were of $94.0632 \%$ of purity and can be used as a standard. The naringin standard curve was shown in Figure 2.

Establishing the correlation of naringi ${ }^{\circ} \mathrm{n}$ concentration against the absorbance resulted in $\mathrm{R}^{2}$ $=0.9954$, suggesting that the standard curve was well fitted through UV Vis spectroscopy with wavelength of $420 \mathrm{~nm}$ and the curve could be used is suitable. From here, use Equation

(3) to determine the amount of naringin based on the measured abs value. 


\subsection{Investigation on the factors that affect reducing the bitterness reduction}

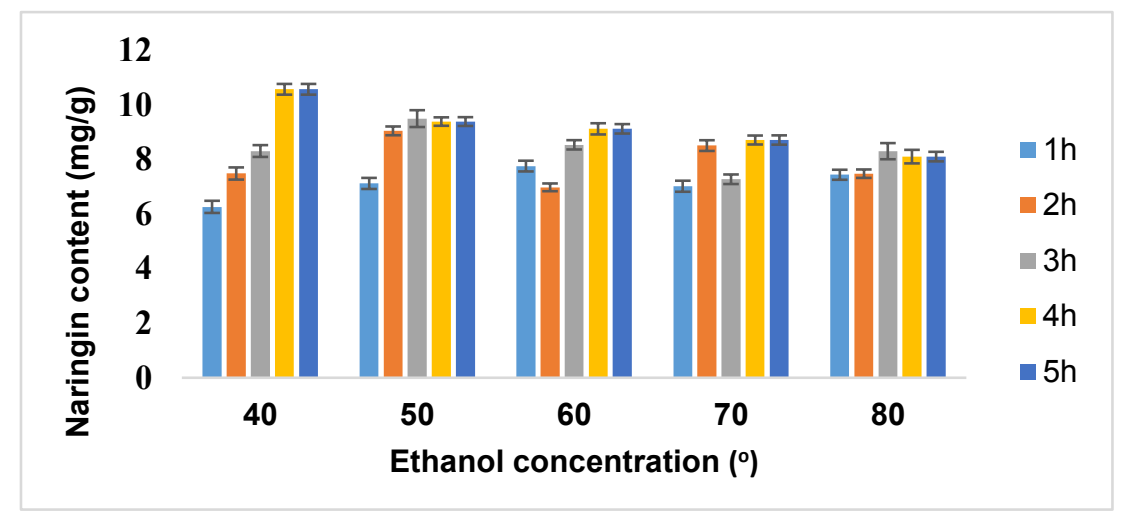

Fig. 3. Effect of ethanol concentration and soaking time on the naringin content

Figure 3 shows the effect of ethanol concentration and soaking time on naringin content. Firstly, when the ethanol concentration increases from $40^{\circ}$ to $80^{\circ}$, the naringin content tends to decrease. The influence of solvent concentration on the antioxidant capacity of plant extracts was explained by the fact that increasing amount of ethanol would dilute the extract, which affects the solubility of naringin in ethanol [17]. Secondly, as can be seen in Figure 3, when extending the soaking time from 1 to $4 \mathrm{~h}$, the naringin content increased and reached the highest value of $10.571 \mathrm{mg} / \mathrm{g}$ at the concentration of $40^{\circ}$ for $4 \mathrm{~h}$. This content remained unchanged when the ethanol soaking was continued to prolong to $5 \mathrm{~h}$. On the other hand, extraction over a long period of time can cause decomposition of chemical compounds [18] and reduce the naringin content in pomelo peel. ANOVA statistical results show that ethanol concentration and soaking time affect naringin content at $95 \%$ confidence level. These two factors interact with each other. prolonged immersion time increases the loss of phenolic compounds including naringin [18-19]. The LSD table showed that $40^{\circ}$ ethanol gave the highest LSM and was different from the remaining concentration; the $4 \mathrm{~h}$ time period was significantly different from $1 \mathrm{~h}, 2 \mathrm{~h}, 3 \mathrm{~h}$, and not different from $5 \mathrm{~h}$. Extraction time is very important in reducing the energy and cost of the extraction process [20]. Therefore, $40^{\circ}$ and $4 \mathrm{~h}$ are selected as suitable parameters to perform next experiments. Zhou et al. (2006) showed a difference with our results where an higher ethanol concentration $\left(50^{\circ}\right)$ and less immersion time (90 minutes) were required to fully extract naringin from pomelo peel.

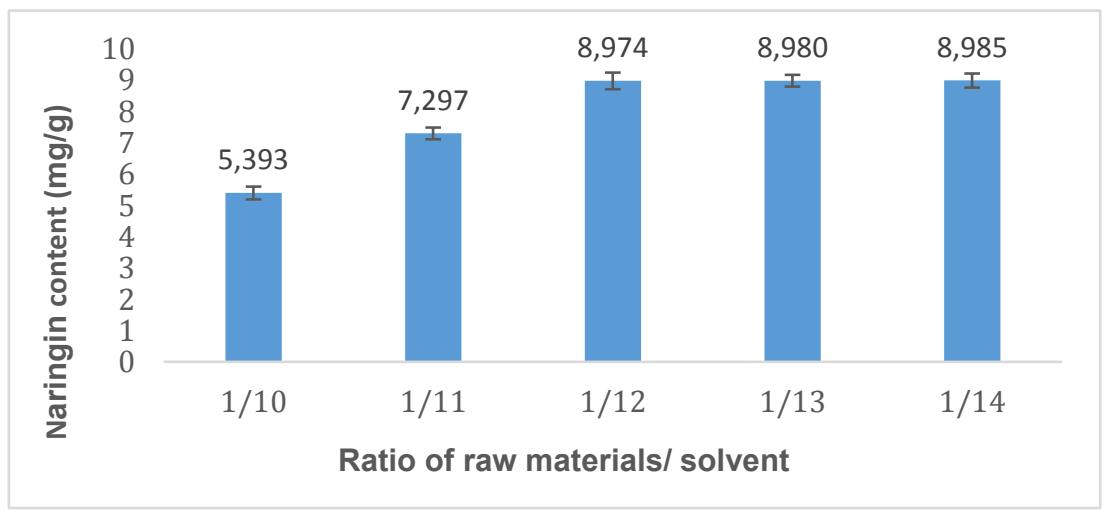

Fig. 4. Effect of material/ solvent volume ratio on naringin content 
The effect of the ratio of material volume / solvent on the naringin glider function is shown in Figure 4. Material / solvent ratio affects the equilibrium constant characteristic of the relationship between yield and solvent use. Achieving the steady state is essential for the best extraction efficiency [21]. When changing the ratio of raw materials / solvents from 1/10 to $1 / 12$, the naringin content increased significantly and reached the highest value of 8,974 $\mathrm{mg} / \mathrm{g}$. However, when changing the ratio to $1 / 13,1 / 14$, the amount of naringin remains unchanged. The high material / solvent ratio increases the gradient concentration leading to an increased rate of diffusion from the material to the solvent and increases the time required to reach equilibrium [22]. When the volume of solvent is too much, it will not only interfere with the extraction of naringin but also dilute the extract, increasing the experimental error. ANOVA statistics table shows that the material / solvent ratio affects naringin content at $95 \%$ confidence level. LSD results show that the yield obtained at ratio $1 / 12$ is significantly different than the those at $1 / 10,1 / 11$ but not different from those at $1 / 13,1 / 14$. So, choosing the ratio of solvent / material $1 / 12$ is reasonable to continue to do the next experiments. Nguyen Cam Van et al (2015) [23] chose 1/10 when surveying the ratio of raw materials / solvents to naringin content from pomelo pulp by ultrasonic extraction method. On the other hand, Zhou et al. (2006) indicated that material / solvent ratio of 1/25 is suitable for maximum naringin yield by leaching method.

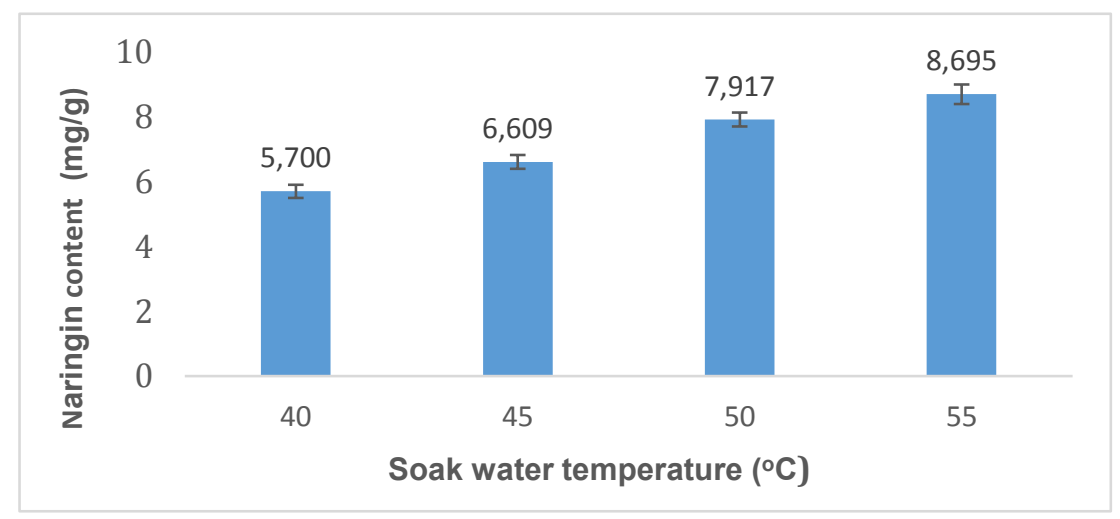

Fig. 5. Effect of the temperature of soaking water on the naringin content

Figure 5 shows the effect of the soaking water temperature on the naringin content. At temperatures of $40^{\circ} \mathrm{C}, 45^{\circ} \mathrm{C}, 50^{\circ} \mathrm{C}, 55^{\circ} \mathrm{C}$, the naringin content increased, respectively, to 5,700 $\mathrm{mg} / \mathrm{g}, 6.609 \mathrm{mg} / \mathrm{g}, 7.917 \mathrm{mg} / \mathrm{g}, 8.695 \mathrm{mg} / \mathrm{g}$. Temperature has a great impact on the physical properties of the extraction solvent, having a great influence on the diffusion and transfer rate of the solute through plant cells into the solvent [24]. ANOVA results with $\mathrm{P}<0.05$ showed that soaking water temperature affects naringin content at $95 \%$ confidence level. The LSD table shows that the $55^{\circ} \mathrm{C}$ temperature resulted in significant difference from results at $40^{\circ} \mathrm{C}$, $45^{\circ} \mathrm{C}, 50^{\circ} \mathrm{C}$. Although the $55^{\circ} \mathrm{C}$ gave better yield, the device was excessively hot and unstable at this temperature. Therefore, the temperature of $50^{\circ} \mathrm{C}$ is chosen to ensure costs, equipment as well as to limit errors during the experiment. Selection results are different from the work of Zhou et al. (2006), Nguyen Cam Van et al (2015) in which $60^{\circ} \mathrm{C}$ and $55^{\circ} \mathrm{C}$ were selected as optimal temperatures, respectively. 
Fig. 6. Effect of number of discharges on naringin content

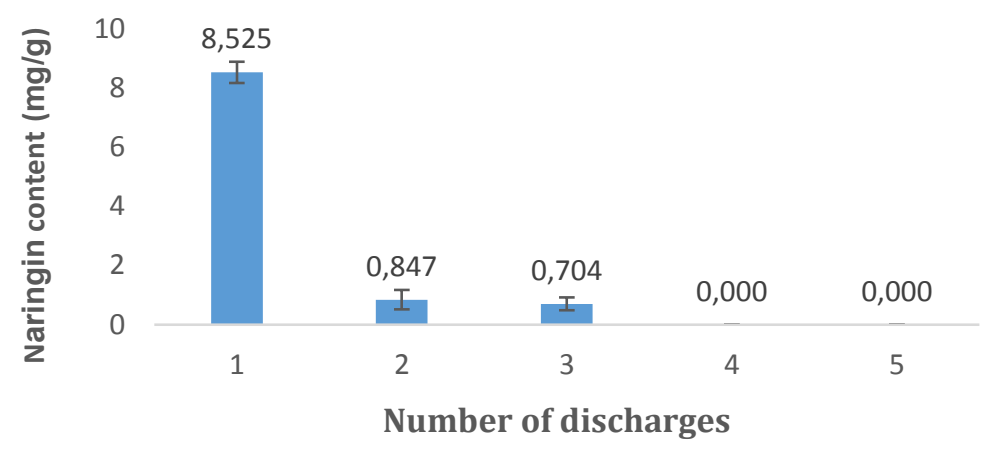

Figure 6 shows the effect of the debitter process on the recovered naringin content. This is the last step for removing the remaining naringin content in the pomelo peel. At the first rinse, the naringin content in the pomelo peel was as high as $8,525 \%$. Then, rapid reduction at the 4th and 5th discharge with naringin content of $0 \mathrm{mg} / \mathrm{g}$. ANOVA results show that the number of discharges influences the reduction of bitterness with $\mathrm{P}<0.05$ at $95 \%$ confidence. LSD results showed that 3 rinses were different from 1, 2 rinses but not 4, 5 rinses. Therefore, 3 rinses were suitable for the test.

\subsection{Comparison of some physicochemical components before and after processing}

Table 3. Some physicochemical components before and after processing

\begin{tabular}{|c|c|c|}
\hline Physicochemical components & Before processing & After processing \\
\hline Vitamin C $(\%)(\mathrm{w} / \mathrm{w})$ & 0.0291 & 0.0057 \\
\hline Glucose $(\%)$ & 0.2996 & 0.086 \\
\hline Sucrose $(\%)$ & 0.5073 & 0.203 \\
\hline Abamectin $(\mu \mathrm{g} / \mathrm{kg})$ & 23.156 & 4.665 \\
\hline Cypermethrin $(\mu \mathrm{g} / \mathrm{kg})$ & 72.721 & 55.51 \\
\hline Chlorpyrifos Ethyl $(\mu \mathrm{g} / \mathrm{kg})$ & 214.58 & 7.535 \\
\hline
\end{tabular}

The physicochemical components was different before and after the de-bitter treatment presented in Table 3. The polarity of the solvent used for extraction may be a decisive factor to increase the extraction efficiency of substances [18]. Because of the high polarity of ethanol with de-bitting process is stronger, losing a large amount of vitamin $\mathrm{C}$, glucose, and sucrose and removing harmful plant protection substances. The bitter removal efficiency obtained was $87.5 \%$.

\section{Conclusion}

The peel of a local variety of pomelo has the contents of moisture, ash, $\mathrm{pH}$, citric acid, glucose, Sucrose, and vitamin C were $76.558 \%, 0.677 \%, 5.153 \%, 2.219 \mathrm{mg} / \mathrm{g}, 0.2996$ \%, $0.5073 \%$, and $0.029 \%$, respectively. The optimum conditions for reducing the pomelo bitter taste by soaking with ethanol include ethanol concentration of $40^{\circ}$, soaking time of $4 \mathrm{~h}$ with a solvent / material ratio of $1 / 12$, soaking temperature of $50{ }^{\circ} \mathrm{C}$ and soaking for 3 times. A highest efficiency of naringin bitterness reduction was obtained as $82.5 \%$. Ethanol, although being capable of eliminating the amount of chemical pesticides, also reduces the amount of beneficial vitamins, glucose, and sucrose. There have been many research works, removing 
bitter grapefruit peel by a number of different methods, but these methods either require complicated equipment or use toxic solvents, causing environmental pollution that is not safe for health. Therefore, there is a need to study to extract this active ingredient with a safe, inexpensive solvent to achieve high efficiency. Therefore, ethanol solvent was chosen for this study.

Acknowledgement. This research was funded by Nong Lam University, Thu Duc District, Ho Chi Minh City, Vietnam.

\section{References}

1. R. W. Hodgson. Horticultural varieties of citrus History, world distribution, botany and varieties. 431-591 (1967)

2. G. Pandove, P. Sahota, and N. Gupta. J. appl. nat. sci. 8, 1649-1653 (2016)

3. H. J. Silver, M. S. Dietrich, and K. D. Niswender. Int. J. Nutr. Metab. 8, 1-11 (2011)

4. A. Giacomo and B. Mincione. Gli olii essenziali agrumari in Italia. 115-129 (1994)

5. A. V. Nunes. Green Process. Synth. (2017)

6. M. Puri, M. L. Verma, and K. Mahale. Flavonoids: Dietary sources, Properties and Health Benefits 443-459 (2012)

7. A. Konno, M. Misaki, J. Toda, T. Wada, and K. Yasumatsu. Agric. Biol. Chem. 46, 2203-2208 (1982)

8. B. Chandler and K. Nicol. CSIRO Food Res Quart. 35 79-88 (1975)

9. K. Hartonen, J. Parshintsev, K. Sandberg, E. Bergelin, L. Nisula, and M.-L. Riekkola. Talanta. 74, 32-38 (2007)

10. G. Raman, M. Cho, J. S. Brodbelt, and B. S. Patil. Int. J. Plant Physiol. Biochem. 16, 155-160 (2005)

11. J. Yu, D. V. Dandekar, R. T. Toledo, R. K. Singh, and B. S. Patil. Food Chem. 105, 1026-1031 (2007)

12. Y. Liang, Z. Huang, H. Chen, T. Zhang, and Y. Ito. J. Liq. Chromatogr. Relat. Technol. J LIQ CHROMATOGR R T. 30, 419-430 (2007)

13. Z. Shilei, W. Hongfei, and D. Jiexiong, Transactions of the Chinese Society of Agricultural Engineering. 07 (2006)

14. M. Le. Kiểm nghiệm và phân tích thực phẩm. (2009)

15. D. Bui. Hóa sinh-Phần III. (2014)

16. H. Le, H. On. Bao cong Thuong. (2018)

17. L. MESSAOUDENE, M. P. LOVILLO, M. HAZZIT, and R. DJEBBAR. Ann. Univ. Buc. Chim. 25 (2018)

18. K. Chew, M. Khoo, S. Ng, Y. Y. Thoo, W. W. Aida, and C. W. Ho. Int. Food Res. J. 18, 1427 (2011)

19. M. Naczk and F. Shahidi. J. Pharm. Biomed. Anal. 41, 1523-1542 (2006)

20. D. L. Luthria, J. Funct. Foods. 4, 842-850 (2012)

21. S. Hamdan, H. G. Daood, M. Toth-Markus, and V. Illés, J Supercrit Fluids J SUPERCRIT FLUID. 44, 25-30 (2008)

22. N. C. Predescu, C. Papuc, V. Nicorescu, I. Gajaila, G. V. Goran, C. D. Petcu, et al., Rev. Chim. 67, 1922-1927 (2016)

23. V.C. Nguyen, C.M. Nguyen, D.V. Dao, Q.T. Nguyen, N.Q. Nguyen, T.V. Nguyen. Tạp Chí Y - Dược Học Quân Sự Số 1 (2015)

24. H. N. Rajha, N. El Darra, Z. Hobaika, N. Boussetta, E. Vorobiev, R. G. Maroun, et al., Food Nutr Sci. 2014, (2014) 